\title{
PENGARUH KEPUASAN DAN MOTIVASI TERHADAP PRODUKTIVITAS KARYAWAN PT. SANTA GREAT INDUSTRY DI JAKARTA
}

\author{
Sherlie Ordelia' ${ }^{1}$ Kurniati W. Andani \\ ${ }^{1}$ Program Studi Manajemen, Fakultas Ekonomi dan Bisnis, Universitas Tarumanagara \\ Email: sherlie.115170252@stu.untar.ac.id \\ ${ }^{2}$ Program Studi Manajemen, Fakultas Ekonomi dan Bisnis, Universitas Tarumanagara* \\ Email: kurniatia@fe.untar.ac.id \\ *Penulis Korespondensi
}

\begin{abstract}
ABSTRAK
Tujuan dari penelitian ini adalah untuk mengetahui pengaruh kepuasan kerja dan motivasi kerja terhadap produktivitas kerja karyawan, dikarenakan produktivitas kerja dari karyawan tidak dapat diukur atau dinilai langsung, maka dalam penelitian ini akan dilihat melalui variabel kepuasan kerja dan motivasi kerja yang dirasakan oleh karyawan. Metode pada penelitian ini menggunakan metode deskriptif dengan jenis penelitian kuantitatif dan menggunakan teknik kuesioner untuk mengumpulkan data. Ukuran sampel yang digunakan pada penelitian ini sebanyak 60 responden. Penelitian ini menggunakan SmartPLS 3. Dengan menggunakan purposive sampling, temuan pada penelitian ini menunjukkan bahwa kepuasan kerja dan motivasi kerja berpengaruh positif dan signifikan terhadap produktivitas kerja karyawan.
\end{abstract}

Kata Kunci: Kepuasan Kerja, Motivasi kerja, Produktivitas

\section{ABSTRACT}

The purpose of this study was to know the effect of job satisfaction and work motivation on employee productivity, because the work productivity of employees cannot be measured or directly assessed, so in this study will be seen through the variables of job satisfaction and work motivation felt by employees. The method in this study uses descriptive methods with quantitative research types and uses questionnaire techniques to collect data. The sample size used in this study were 60 respondents. This study uses SmartPLS 3. By using purposive sampling, the findings of this study indicate that job satisfaction and work motivation have a positive and significant effect on employee work productivity.

Keywords: Job Satisfaction, Work Motivation, Productivity

\section{PENDAHULUAN}

\section{Latar Belakang}

Dalam suatu perusahaan pasti diperlukannya SDM (Sumber Daya Manusia) untuk mencapai tujuan dari organisasi atau perusahaan tersebut. Namun, di dalam suatu pekerjaan terutama pada sebuah organisasi atau perusahaan, tidak semua individu atau orang dapat bekerja dengan baik, yang dimaksud dengan baik adalah memiliki semangat kerja, tidak malas-malasan dan sebaginya yang dimana pada dasarnya bisa memenuhi kriteria dan harapan yang diinginkan oleh perusahaan juga kemampuan untuk bertahan atau beradaptasi dengan lingkungan kerja serta memiliki kemampuan untuk mengembangkan perusahaan tersebut. Oleh karena harapan atau target dari suatu perusahaan terhadap sumber daya manusianya atau karyawan, banyak permasalahan yang sering muncul seperti beberapa karyawan yang kinerjanya lebih produktif dibandingkan dengan karyawan lain. Hal ini merupakan masalah yang selalu dihadapi oleh banyak pimpinan kerja karena seringkali ditemukan karyawan yang mempunyai kemampuan dan 
ketrampilan serta semangat kerja yang sesuai dengan harapan organisasi, dan ada pula karyawan yang mempunyai kemampuan dan ketrampilan tetapi tidak mempunyai semangat kerja yang tinggi, sehingga kinerja tidak sesuai dengan harapan organisasi.

Dalam lingkungan pekerjaan produktivitas karyawan sangatlah penting, karena produktivitas karyawanlah yang mencerminkan kualitas kinerja seseorang. Produktivitas kerja juga dipengaruhi oleh beberapa faktor. Terdapat faktor positif yang berdampak pada peningkatan produktivitas kerja dan ada juga faktor negatif yang berdampak pada penurunan produktivitas kerja. Beberapa faktor yang dapat mempengaruhi produktivitas kerja seorang karyawan seperti kepuasan kerja dan motivasi kerja. Seperti pada penelitian yang dilakukan oleh Viona Malonda, memiliki tujuan untuk mengetahui adakah pengaruh dari kepuasan kerja dan motivasi kerja terhadap produktivitas kerja karyawan. Dari pengujian penelitian tersebut, maka didapatkan hasil bahwa adanya pengaruh positif dari kepuasan kerja dan motivasi kerja terhadap produktivitas kerja karyawan.

Oleh karena permasalahan yang dihadapi oleh pihak perusahaan PT. Santa Great Industry di Jakarta yang juga membutuhkan karyawan yang sesuai dengan harapan perusahaan dalam arti produktivitas karyawan itu sendiri, dimana produktivitas karyawan mempengaruhi perkembangan perusahaan tersebut. Maka dilakukan penelitian ini dengan menambahkan indikator-indikator variabel yang dapat mempengaruhi hubungan variabel tersebut.

\section{Kajian teori}

Pada suatu perusahaan, produktivitas kerja karyawan sangatlah penting karena produktivitas kerja karyawan akan berdampak pula pada produktivitas perusahaan yang mempengaruhi nilai suatu perusahaan itu sendiri. Dalam hal ini, produktivitas dapat dipengaruhi oleh berbagai faktor atau variabel seperti kepuasan kerja karyawan dan juga motivasi kerja karyawan itu sendiri.

Untuk kepuasan kerja, Mexley dan Yukl (1977) teori mengenai variabel tersebut yang dibagi menjadi tiga teori, yaitu; Discrepancy Theory (Teori Perbandingan Intrapersonal), Equity Theory (Teori Keadilan), dan Two Factor Theory (Teori Dua Faktor). Abraham H. Maslow juga berpendapat mengenai motivasi kerja, bahwa "individuals must satisfy lower level deficit needs before progressing on to meet higher level growth needs.", tingkatan atau hirarki itu terdiri dari; kebutuhan fisiologis (physiological needs), kebutuhan rasa aman (safety needs), kebutuhan akan kasih sayang dan diterima oleh orang lain (social needs), penghargaan (esteem needs), dan aktualisasi diri (self actualization). Seperti pada gambar dibawah ini. Sedangkan, produktivitas kerja menurut Aiyetan dan Olotuah (2006), ditunjukkan pada output yang dikeluarkan oleh karyawan itu dengan input yang diterimanya. Output yang dimaksud berupa hasil yang dikerjakan apakah efektif dan efesien, sedangkan output yang dimaksud berupa faktor- faktor yang terjadi selama proses kerja.

Pada penelitian yang dilakukan oleh Dennis M. Daley (2017), Dennis dalam penelitiannya berpendapat bahwa "global satisfaction and job engagement, composed of distinct, nonoverlapping items, share two factor analysis categories in common: Leadership (managerial leadership and organizational commitment) and Work Experience (intrinsic motivation)" sehingga dapat disimpulkan bahwa kepuasan kerja dan motivasi saling berkaitan, dimana kepuasan kerja dapat ditentukan juga oleh pengalaman kerja yang mana merupakan motivasi dari dalam diri individu. Menurut Sirait (2006:249), ada beberapa faktor yang dapat menimbulkan produktivitas karyawan. Adapun faktor-faktor tersebut adalah: 1) Faktor pendidikan dan pelatihan, antara lain: membentuk, menambah, dan memperluas pengetahuan dan keterampilan 
kerja seseorang; 2) Faktor gizi dan kesehatan, yaitu makan makanan yang mengandung gizi cukup sehingga karyawan menjadi semangat; 3) Faktor motivasi, yaitu cara mempengaruhi seseorang untuk melakukan sesuatu; 4) Faktor kesempatan kerja, antara lain: kesempatan seseorang untuk bekerja, dan pekerjaan yang sesuai dengan pendidikan dan keterampilan pekerja. Menurut Davis dan Newstrom (1992), mengemukakan bahwa "kepuasan kerja mempunyai pengaruh yang cukup besar terhadap produktivitas suatu organisasi secara langsung maupun tidak langsung maupun tidak langsung." Lalu pada penelitian yang dilakukan oleh Viona Malonda, memiliki tujuan untuk mengetahui adakah pengaruh dari kepuasan kerja dan motivasi kerja terhadap produktivitas kerja karyawan. Dari pengujian penelitian tersebut didapatkan hasil bahwa adanya pengaruh positif dari kepuasan kerja dan motivasi kerja terhadap produktivitas kerja karyawan.

Berikut Gambar 1 di bawah ini merupakan kerangka pemikiran dari penelitian ini:

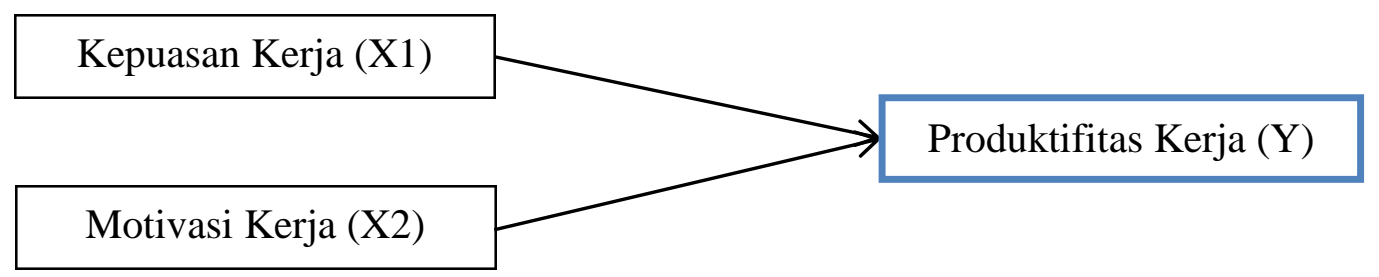

Gambar 1. Kerangka pemikiran

\section{Hipotesis}

H1: terdapat pengaruh yang positif dan signifikan antara kepuasan kerja dan produktivitas kerja. $\mathrm{H} 2$ : terdapat pengaruh yang positif dan signifikan antara motivaasi kerja dan produktivitas kerja.

\section{METODE PENELITIAN}

Desain penelitian ini menggunakan penelitian deskriptif. Menurut Sugiyono (2011) "penelitian deskriptif adalah penelitian yang bertujuan untuk menyediakan atau menjabarkan suatu keadaan atau fenomena yang terjadi saat ini dengan menggunakan prosedur ilmiah untuk menjawab masalah yang aktual.”. Dimana desain penelitian ini sesuai dengan penelitian yang mencari pengaruh kepuasan kerja dan motivasi kerja terhadap produktivitas kerja karyawan. Untuk operasional variabel, pada variabel kepuasan kerja menggunakan empat indikator yaitu lingkungan kerja, gaji/upah, rekan kerja, dan tugas yang diberikan. Untuk variabel motivasi kerja menggunakan indikator perilaku atasan, keinginan untuk memperoleh penghargaan, dan tunjangan yang diberikan, sedangkan untuk variabel produktivitas kerja menggunakan indikator ketepatan waktu, kualitas kerja, dan kuantitas dari kerja yang dihasilkan.

Dalam penelitian ini tidak meneliti keseluruhan populasi, tetapi dengan sampel dimana menggunakan purposive sampling. Menurut Duli (2019), purposive sampling merupakan teknik pengambilan sampel yang didasari oleh suatu pertimbangan tertentu. Sampel juga dibatasi sebanyak 60 responden yang mengacu pada Roscoe (1975), sampel yang digunakan antara 30 sampai dengan 500.

Untuk mengolah hasil data yang telah diperoleh, penelitian ini menggunakan program PLS (Partial Least Squares) merupakan salah satu statistika yang banyak digunakan dalam penelitian ilmu-ilmu sosial maupun eksakta. PLS menggunakan metode bootstraping atau penggandaan secara acak. Karena dilakukannya bootstraping PLS juga tidak memiliki syarat minumum sampel sehingga dapat digunakan dalam perhitungan dengan sampel yang kecil. Pada pengujian statistik atau hipotesis, penelitian ini menggunakan uji t-statistik, dimana menurut Ghozali 
(2011), uji statistik t atau uji hipotesis ini pada dasarnya bertujuan untuk mengetahui seberapa jauh pengaruh satu variabel penjelas atau independen secara individual dalam menerangkan variasi variabel dependen.

\section{HASIL DAN PEMBAHASAN}

Dari penelitian pada PT. Santa Great Industry, diperoleh 60 responden dari keseluruhan populasi karyawan pada perusahaan tersebut. Responden di dominasi oleh karyawan perempuan dengan usia antara 20-30 tahun dan pendidikkan terakhir D3 serta lama bekerja di perusahaan antara 1 sampai 5 tahun. Kuesioner menggunakan skala likert 5 poin, sehingga responden menjawab suatu pernyataan dengan memilih poin yang paling sesuai dengan yang mereka alami.

Uji validitas diukur dengan menggunakan nilai convergent validity, average variance extracted (AVE) dan discriminant validity. Pada penelitian ini convergent validity dinilai berdasarkan faktor loading atau outer loading, nilai nilai faktor loading lebih besar daro 0,5 yang artinya berada pada tingkat nilai yang cukup, yaitu nilai terendah di 0,538. Pada $A V E$ masing-masing variabel juga memperoleh nilai lebih besar dari 0.5 sehingga terbukti telah mengukur kontruk pada variabel-variabel dan dapat dikatakan memiliki nilai validitas yang baik. Lalu pada pengujian yang menggunakan nilai discriminant validity dengan cross loading dapat dikatakan bahwa indikator variabel tersebut valid, jika nilai korelasi antara variabel harus menunjukkan nilai yang lebih besar pada variabelnya sendiri dibandingkan dengan nilai pada korelasi variabel yang lainnya. Pada KK1 terhadap KK (Kepuasan Kerja) nilainya sebesar 0,764, yang artinya nilai tersebut lebih besar dibandingkan variabel konstruk lainnya, dimana pada variabel MK (Motivasi Kerja) sebesar 0,645 dan pada variabel PK (Produktivitas Kerja) sebesar 0,590, yang artinya nilai variabel konstruk lain lebih kecil.

Selanjutnya pada pengujian analisis reabilitas menggunakan Composite Realibilty dan Cronbach"s Alpha. Hasil composite reliability dikatakan valid jika memiliki nilai diatas 0.7, sehingga pada penelitian ini nilainya valid karena masing-masing variabel memiliki nilai yang lebih besar dati 0.7. Sedangkan, pada nilai alpha atau composite reliability harus lebih besar dari 0,7 meskipun nilai 0,6 masih dapat diterima (Hair et al. 2008). Hasil penelitian menunjukkan masing-masing variabel memiliki nilai lebih besar dari 0,7 sehingga dapat diterima atau valid.

Berdasarkan pengujian koefisien determinasi hasilnya menunjukkan bahwa nilai $R$-square dari produktivitas kerja sebesar 0.733 yang artinya adalah variansi perubahan variabel dependen sebesar 73.3\% dijelaskan oleh variabel independen (Kepuasan Kerja dan Motivasi Kerja) dan sisanya sebesar $26.7 \%$ dijelaskan oleh variabel diluar model yang diteliti. Sehingga nilai koefisien determinasinya menunjukkan bahwa variabel independen mampu menjelaskan variabel dependennya. Lalu pada pengujian kecocokkan atau Godness of Fit/GoF nilai NFI sebesar 0.674, dimana nilai pengujian NFI berkisar antara 0-1 dan NFI dapat dikatakan baik apabila nilai semakin mendekati 0.9. Pengujian selanjutnya adalah pengujian hipotesis (uji t-statistik) yang bertujuan untuk mengetahui apakah terdapat pengaruh yang signifikan antar variabel.

Tabel 1. Hasil Uji Hipotesis (Uji t-statistik)

Sumber: Hasil pengolahan data menggunakan software SmartPLS 3

\begin{tabular}{|l|c|c|c|c|c|}
\hline & $\begin{array}{c}\text { Original Sample } \\
(\boldsymbol{O})\end{array}$ & $\begin{array}{c}\text { Sample Mean } \\
(\boldsymbol{M})\end{array}$ & $\begin{array}{c}\text { Standard Deviation } \\
(\text { STDEV })\end{array}$ & $\begin{array}{c}\boldsymbol{t} \text {-statistic } \\
(\mid \boldsymbol{O} / \text { /STEDEV })\end{array}$ & $\boldsymbol{p}$-values \\
\hline $\begin{array}{l}\text { Kepuasan Kerja } \rightarrow \\
\text { Produktivitas Kerja }\end{array}$ & 0.287 & 0.303 & 0.135 & 2.120 & 0.034 \\
\hline $\begin{array}{l}\text { Motivasi Kerja } \rightarrow \\
\text { Produktivitas Kerja }\end{array}$ & 0.598 & 0.588 & 0.135 & 4.497 & 0.000 \\
\hline
\end{tabular}


Berdasarkan Tabel 1, dapat disimpulkan bahwa kepuasan kerja dan motivasi kerja memiliki pengaruh yang positif dan signifikan terhadap produktivitas kerja.

\section{Diskusi}

Dari hasil penelitian yang dilakukan pada karyawan PT. Santa Great Industry di Jakarta dengan jumlah responden sebanyak 60 responden, maka hasil yang dapat disimpulkan terkait dengan pengujian hipotesis adalah sebagai berikut:

H1 : terdapat pengaruh yang positif dan signifikan antara kepuasan kerja dan produktivitas kerja. Dari hasil analisis penelitian yang telah dilakukan, dapat disimpulkan bahwa terdapat pengaruh positif dan signifikan antara variabel kepuasan kerja terhadap produktivitas kerja. Hal ini dapat dilihat dari pengujian hipotesis dimana nilai $\mathrm{T}$ value 2.120 lebih besar dari 1.96. Dalam pengujian koefisien determinasi juga menunjukkan variabel independen dapat menjelaskan variabel dependennya sebesar $73.3 \%$. Hasil penelitian ini juga diperkuat oleh penelitian terdahulu dari Halkos, George dan Bousinakis, Dimitrios (2009) yang menyatakan bahwa produktivitas kerja sangat dipengaruhi oleh dua faktor, yaitu stress dan kepuasan kerja yang dimana pengaruh tersebut memiliki pengaruh yang signifikan terhadap produktivitas kerjanya. Selain itu terdapat juga penelitian dari Malonda, Viona (2013) yang menyatakan bahwa secara positif kepuasan kerja dan motivasi kerja berpengaruh secara stimulan terhadap produktivitas kerja karyawan.

H2 : terdapat pengaruh yang positif dan signifikan antara motivaasi kerja dan produktivitas kerja. Dari hasil analisis penelitian yang telah dilakukan, dapat disimpulkan bahwa terdapat pengaruh positif dan signifikan antara variabel motivasi kerja terhadap produktivitas kerja. Hal ini dapat dilihat dari pengujian hipotesis dimana T value sebesar 4.497 sehingga nilainya lebih besar dari 1.96. Dalam pengujian koefisien determinasi juga menunjukkan variabel independen dapat menjelaskan variabel dependennya sebesar $73.3 \%$. Hasil penelitian ini diperkuat juga oleh penelitian terdahulu dari Purnama, Ridwan (2008) yang menyataka bahwa motivasi kerja berpengaruh secara positif dan signifikan terhadap produktivitas kerja karyawan. Selain itu Malonda, Viona (2013) juga menyatakan bahwa secara kepuasan kerja dan motivasi kerja berpengaruh secara stimulan terhadap produktivitas kerja karyawan. Viona juga mengatakan bahwa motivasi kerja sendiri berpengaruh positif dan signifikan terhadap produktivitas kerja karyawan.

\section{KESIMPULAN DAN SARAN}

Dari hasil penelitian yang telah dilakukan untuk mengetahui pengaruh kepuasan kerja dan motivasi kerja terhadap produktivitas kerja karyawan PT. Santa Great Industry di Jakarta, maka peneliti memperoleh kesimpulan, sebagai berikut:

1. Kepuasan kerja memiliki pengaruh yang positif dan signifikan terhadap produktivitas kerja karyawan.

2. Motovasi kerja memiliki pengaruh yang positif dan signifikan terhadap produktivitas kerja karyawan.

Berdasarkan hasil penelitian tersebut juga terdapat saran yang dapat diambil dari hasil penelitian yang telah dilakukan dan kiranya dapat bermanfaat bagi perusahaan dan peneliti lain, sebagai berikut:

1. Bagi perusahaan

Untuk meningkatkan produktivitas karyawan, pada penelitian ini terdapat dua variabel yang mempengaruhinya yaitu, kepuasan kerja dan motivasi kerja. Dari hasil penelitian yang telah dilakukan, pada variabel kepuasan kerja indikator penilaian yang ada hasilnya sudah baik dan 
perlu dipertahankan. Indikator dengan nilai terendah dibanding indokator lain terdapat pada indikator "Saya menerima gaji/ upah tepat pada waktu yang telah disepakati." yang kiranya dapat ditingkatkan lagi. Sedangkan, untuk variabel motivasi kerja hasil penelitiannya juga sudah baik dan perlu dipertahankan. Pada variabel ini indikator penilaian yang terendah terdapat pada indikator "Saya mendapatkan bonus jika mencapai target." yang kiranya juga dapat ditingkatkan lagi pemberian bonus agar karyawan dapat semakin termotivasi dan berdampak pula pada peningkatan produktivitas.

\section{Bagi peneliti lain}

Berdasarkan hasil penelitian yang didapat, produktivitas kerja karyawan dipengaruhi oleh kepuasan kerja dan motivasi kerja dengan hasil yang memiliki pengaruh yang positif dan signifikan, sehingga untuk peneliti lain yang ingin meneliti dapat memakai variabel tersebut dengan indikator- indikator yang ada ataupun menambah lagi indikator penilainya. Untuk peneliti lain yang ingin meneliti tentang variabel ini bisa memberbanyak sampel yang ada agar hasil penelitian lebih bervariasi.

\section{REFERENSI}

Abdulrani, Sulaiman and Asnawi, Asnawi and Matriadi, Faisal. 2014. Pengaruh Pemberdayaan, Self Efficacy Dan Budaya Organisasi Terhadap Kinerja Karyawan PT. Surya Madistrindo Cabang Lhokseumawe Dengan Kepuasan Kerja Sebagai Variabel Intervening. Jurnal Ekonomi, Manajemen dan Akuntansi. 4(1):26-37.

Ahmed A. Al Araimi. 2013. Exploratory Study on Employees' Motivation in The Omani Private Banking Sector. International Journal of Organization Theory and Behavior. 16 (2): 208220.

Aiyetan, A O and Olotuah, A O. 2006. Impact of motivation on workers' productivity in the Nigerian construction industry. In: Boyd, D (Ed) Procs 22nd Annual ARCOM Conference, Birmingham, UK, Association of Researchers in Construction Management. 239-248.

Apridar, and Adamy, M. 2018. The Effect of Job Satisfaction and Work Motivation on Organizational Commitment and Organizational Citizenship Behavior in BNI in the Working Area of Bank Indonesia Lhokseumawe. Proceedings of MICoMS 2017 (Emerald Reach Proceedings Series). 1:1-5.

Arda, M. 2017. Pengaruh Kepuasan Kerja dan Disiplin Kerja Terhadap Kinerja Karyawan pada Bank Rakyat Indonesia Cabang Putri Hijau Medan. Jurnal Ilmiah Manajemen dan Bisnis. 18(1): 45-60.

Aristayudha, A. A., and Netra, S. K.. 2013. Pengaruh Budaya Organisasi, Kepemimpinan dan Motivasi Terhadap Kinerja Karyawan Pada PT BPD Bali Cabang Renon. E-jurnal Manajemen Universitas Udayana. 2(7): 831- 844.

Baker, E., Avery, G. C. \& Crawford, J. 2007. Satisfaction and Perceived Productivity when Professionals Work From Home. Research and Practice in Human Resource Management. 15(1): 37-62.

Battaglia, Michael P. 2008. Encyclopedia of Survey Research Methods. Thousand Oaks: SAGE Publications, Inc.

Budiaji, Weksi. 2013. Skala Pengukuran Dan Jumlah Respon Skala Likert. Jurnal Ilmu Pertanian dan Perikanan. 2(2): 127-133.

Daley, Dennis M. 2017. Job satisfaction versus job engagement: A comparative analysis on perceptions of accountability and turnover. International Journal of Organization Theory \& Behavior. 20(2):161-192.

Davis, K. dan J.W. Newstrom. 1992. Perilaku dalam Organisasi (terjemahan: Agus Dharma). Jakarta: Erlangga. 
Duli, N. (2019). Metodologi Penelitian Kuantitatif: Beberapa Konsep Dasar Untuk Penulisan Skripsi \& Analisis Data Dengan SPSS. Yogyakarta: Penerbit Deepublish.

Ghazzawi, Issam. 2008. Antecedents and Consequences of Job Satisfaction: A New Conceptual Framework. The Business Review, Cambridge. 11(2):1- 10.

Ghozali, Imam. 2011. Aplikasi Analisis Multivariate dengan Program IBM SPSS 19. Semarang: Badan Penerbit Universitas Diponegoro.

Hair. 2006. Multivariate Data Analysis, Fifth Edition. New Jersey: Prentice Hall.

Hair, J., et al. 2014. Partial least squares structural equation modeling (PLS- SEM): An emerging tool in business research. European Business Review. 26(2): 106-121.

Halkos, G., and Bousinakis, D. 2010. The effect of stress and satisfaction on productivity. International Journal of Productivity and Performance Management. 59(5): 415-431.

Hanaysha, Jalal. 2016. Improving employee productivity through work engagement: Evidence from higher education sector. International Journal of Industrial Engineering Computations. 6(1):61-70.

Hanaysha, Jalal dan Majid, Muhammad. 2018. Employee Motivation and its Role in Improving the Productivity and Organizational Commitment at Higher Education Institutions. Journal of Entrepreneurship and Business. 6(1):17-28.

Hussein, A. S. 2015. Penelitian Bisnis dan Manajemen Menggunakan Partial Least Square (PLS) dengan smartPLS 3.0. Universitas Brawijaya.

Ihsani, N., and Wijayanto, A. 2020. The Effect of Organizational Culture, Motivation and Job Satisfaction on Employee Performance. Dinasti Internasional Journal of Digital Business Management. 1(4):492-502.

Justine, T. S. 2006. Memahami Aspek-Aspek Pengelolaan Sumberdaya Manusia dalam Organisasi. Jakarta: PT. Grasindo.

Kuranchie, E. B. and Amponsah, K. 2015. Employee Motivation and Work Performance: A Comparative Study of Mining Companies in Ghana. Journal of Industrial Engineering and Management. 9(2): 255-309

Malonda, Viona. 2013. Kepuasan Dan Motivasi Kerja Pengaruhnya Terhadap Produktivitas Kerja Karyawan Pt. Matahari Megamall Manado. Jurnal Emba: Jurnal Riset Ekonomi, Manajemen, Bisnis Dan Akuntansi. 1(3): 969-979.

Murphy, G., Athanasou, J. and King, N. 2002. Job Satisfaction and Organizational Citizenship Behaviour: A Study of Australian Human- Service Professionals. Journal of Managerial Psychology. 17(4):287- 297.

Octaviannand, R., Pandjaitan, N. K., Kuswanto, S. 2017. Effect of Job Satisfaction and Motivation Toward Employee Peformance in XYZ Shipping Company. Journal Of Education and Practice. 8(8): 72-79.

Pitasari, N., and Perdhana, M. 2018. Kepuasan Kerja Karyawan: Studi Literatur. Diponegoro Journal of Management. 7(4): 1-11.

Purnama, Ridwan. 2008. Pengaruh Motivasi Kerja terhadap Produktivitas Kerja Karyawan pada Bagian Produksi Cv. Epsilon Bandung. Stratrgic Jurnal Pendidikan Manajemen Bisnis. 7(14), 58-82.

Robbins, S. P., \& Judge, T. A. 2015. Organizational Behavior (16th ed.). England: Pearson Education, Inc.

Roscoe, J. . 1975. Fundamental research statistics for the behavioural sciences (2nd ed.). New York: Holt Rinehart \&amp; Winston.

Salaria, Neeru. 2012. Meaning Of The Term-Descriptive Survey Research Method. International Journal of Transformations in Business Management. 1(6).

Shofiyah, Noly. 2015. Deskripsi Literasi Sains Awal Mahasiswa Pendidikan IPA Pada Konsep IPA. Journal Pedagogia Issn 2089 -3833. 4(2):113-120. 
Sugiyono. 2011. Metode Penelitian Kuantitatif Kualitatif DAN R\&D. Bandung: Alfabeta

Thanos, C. A., et al. 2015. The Effect of Job Satisfaction and Employee Motivation on Employee Loyalty (Case Study of PT. Kimia Farma Apotek in Sam Ratulangi, Manado). Jurnal Berkala Ilmiah Efisiensi. 15(4): 313-321.

Wexley, K. N. and Yukl, L. A. 1988. Organizational Behavior and Personnel Psychology. Boston: Richard D. Irwin, Inc..

Wiryanti, N. M., 2017. Pengaruh Supervisi Dan Motivasi Intrinsik Terhadap Kreativitas Guru SD Swasta Katolikdi Jakarta Timur. Jurnal Manajemen Pendidikan. pp 150-161.

Zameer, Hashim., et al. 2014. The Impact of the Motivation on the Employee's Performance in Beverage Industry of Pakistan. International Journal of Academic Research in Accounting, Finance and Management Sciences. 4(1):293-2. 